\title{
ALTERNATIVAS DE LA CULTURA. UNA LECTURA MATERIAL DEL DUELO DEL 11-M
}

\section{CULTURE ALTERNATIVES. A MATERIAL READING OF THE MOURNING OF 11th-M}

\author{
Pilar Jimeno Salvatierra \\ Universidad Autónoma de Madrid. España/Spain \\ pilar.jimeno@uam.es \\ pilarjimeno@hotmail.com
}

Recibido/Received: 07/05/09

Modificado/Modified: 27/09/09

Aceptado/Accepted: 07/10/09

\begin{abstract}
RESUMEN
A partir del planteamiento de la ecología humana se produce una ruptura en las formas de estudiar la cultura o sus realizaciones. La novedad tiene que ver con la necesidad de examinarla no en sí misma o en sus interpretaciones, sino como un elemento del sistema ecológico que está interconectado con el resto de sus elementos materiales. Este modelo de análisis funcional material, será calificado de substantivista por algunos de sus principales teóricos. Así los comportamientos culturales son respuestas a las perturbaciones del entorno perteneciente al propio sistema. Una de las más interesantes para el estudio de lo social y cultural son los rituales, que forman parte de mecanismos retroactivos dentro de cualquier sistema ecológico humano. Este escrito propone una forma de observar el aspecto material de los comportamientos colectivos, ya se trate de rituales, ceremoniales $\mathrm{u}$ otro tipo de manifestaciones colectivas, para reclamar la importancia ecológica, social e interpretativa que tienen estos aspectos. Pretende hacer ver además tanto la parte de creación como el sentido de la asignación de significados sociales, mediante el examen de los comportamientos colectivos, capaces de mostrar en sus manifestaciones materiales una parte importante de verdad social. Para ello se utilizan algunas de las aplicaciones metodológicas que sugiere Rappaport haciendo referencia a su teoría de los signos materiales en el ritual, concediendo la máxima importancia a su papel comunicador.
\end{abstract}

\section{PALABRAS CLAVE}

Sistema ecológico, comportamientos colectivos, adaptación, nuevos rituales, cultura ciudadana.

\begin{abstract}
Since the human ecology approach occurs a break in the forms of studying culture or its accomplishments. The novelty has to do with the need to examine it not in itself or in their performances, but as an element of the ecological system is interconnected with the rest of their material elements. This material functional analysis model is described as a substantive by its main theoretical. Thus the cultural behaviours are responses to disturbances belonging to the system environment. One of the most interesting for the study of social and cultural are rituals, as part of retroactive mechanisms within any human ecological system. The aims of this paper is to theorize about the observation of the material aspects of collective behaviours, such as rituals, ceremonies, or
\end{abstract}


others collective manifestations, that highlight the social importance and interpretative of these aspects. The article manifests both the creation and the orientation of "enactment of meanings" through the analysis of collective behaviours. It also shows an important part of social truth in material performances. Methodological applications such as Rappaport's reference to material signs in his ritual theory, placing emphasize on the communication role of these are used to interpret the mourning ritual.

\section{KEYWORDS}

Ecological system, collective behaviours, adaptation, new rituals, citizen culture.

\section{INTRODUCCIÓN}

Intento plantear aquí un análisis de los nuevos comportamientos ciudadanos, que fueron observados en torno al espontáneo ritual elaborado alrededor de los atentados del 11-M, que tuvieron lugar en 2004 en Madrid, comparando las formas de comunicación más habituales de la especie humana, como es el ritual, con otras formas de comunicación, sobre todo la mediática y la virtual además de su papel en el duelo por las víctimas de la masacre. Muestro además las características de los nuevos rituales, que aparecen desvinculados de las instituciones religiosas como una característica de los nuevos comportamientos ciudadanos.

Algunos antecedentes teóricos los encontramos en el transcurso del pasado siglo cuando tiene lugar el desarrollo de las teorías principales que versan sobre las acciones colectivas, uno de cuyos tipos fue denominado 'ritual' por autores que atraviesan las ciencias sociales entre los que podemos encontrar tanto a Durkheim cuanto a Weber o R. Rappaport. Durante tan dilatado espacio de tiempo, hemos podido comprobar cómo los rituales eran considerados como algo que podía ser previo a la religión, existen citas de Durkheim muy claras en este sentido. Muchos años después Rappaport los considera sinónimos de la construcción de lo sagrado desde un punto de vista ecológico, como un programa regulador del propio sistema ecológico en su estructura jerárquica (biológica). Dentro de esta perspectiva ecológica el elemento que constituye de forma preferente un ritual son las acciones colectivas, teorizadas como comportamientos a partir de una lectura material o substancial de los propios rituales, que representan mediante signos e índices.

Por otra parte las teorías sobre la secularidad y modernización, que van desde Kant (y antes la Reforma) a nuestros días, se ocupan de hacernos percibir nuestros credos morales de forma tan individual como abstracta, aparecen morales y éticas formales o intencionales capaces de elaborar constituciones, derechos humanos y consensos ejemplarizantes, todo ello pertenece a la historia, pero si se consideran, por otra parte, los sucesos históricos y políticos que se producen en la última mitad del s. XX, puede observarse que provocan una conciencia de representaciones colectivas que invierte hacia el otro lado de la balanza el equilibrio entre lo individual y lo colectivo, inclinándose esta vez hacia lo colectivo y plural no sólo mediante nuevas formulaciones políticas, sino también identitarias, reales e imaginarias ${ }^{1}$

Voy a poner un ejemplo teóricamente alternativo, por ser material su punto de partida, a todos esos corpus simbólicos o éticos y referirme simplemente a una lectura material de los sucesos del 11-M, que pueden ofrecer alguna luz, sólo capaz de revelarse observando el lado aparentemente oscuro y mudo de lo material, sin duda, aquí, expresión 
del aspecto político e ideológico. Con ello intento proponer algunas formas de observar el aspecto material de las acciones colectivas, ya se trate de rituales, de ceremoniales o simplemente de acciones para reclamar la importancia social e interpretativa de estos aspectos de la cultura, y hacer ver también la perspectiva de creación, en el sentido de Castoríadis, de las acciones humanas confeccionadoras de historia y cultura, capaces a su vez de mostrar mediante sus manifestaciones materiales, una parte importante de verdad social, es decir como imaginario radical. Para ello utilizaré algunas de las aplicaciones metodológicas que sugiere Rappaport respecto a la teoría de los signos materiales en el ritual, concediendo la máxima importancia a su papel comunicador.

Recordemos que a principios del siglo pasado Durkheim venía a invertir la óptica individualista de la moral protestante o kantiana con una perspectiva otra vez colectiva que le asimilará a planteamientos antropológicos. La religión era para él un "hecho social", y sobre todo estaba compuesta por actuaciones colectivas, los ritos. Más allá de las creencias, el autor pensaba que los rituales eran más bien actuaciones colectivas obligatorias que se imponían en la sociedad con fuerza coercitiva ${ }^{2}$. Muchos años más tarde Rappaport vuelve a rescatar, sobre todo en su última obra (Rappaport, 1999), un planteamiento similar en el sentido de priorizar el ritual sobre las creencias. El ritual es para este autor principalmente convocatoria, pacto, consentimiento o aquiescencia entre los que allí van, de forma relativamente independiente de los contenidos formales que pudieran convocar. Según él la religión se basa centralmente en un comportamiento adaptativo y actualizado, donde la actuación ritual es sagrada, sobre todo, por ser creadora de reunión, pacto social o consenso, así como por comunicar el estado actual de quienes protagonizan el ritual.

El lenguaje de la comunicación de lo substancial de los signos que es empleado por el ritual es tal, que no tiene equivalentes mediante otros lenguajes, puesto que es capaz de comunicar más y con mayor verdad, sobre todo si nos atenemos a la lectura de los elementos materiales. Esta verdad material es indicativa y pertenece al aspecto autorreferencial que todo ritual posee, y por esta razón no está sujeta a las alternativas propias del lenguaje, sino que simplemente muestra los parámetros del mundo en su actualidad material y física en referencia al sistema ecológico y también a la estructura social, considerándolo por ello una forma que transmite mayor verdad, que la interpretación simbólica usualmente asociada a cualquier ritual.

Es conocida la analogía empleada por el autor al hablar del ritual como si fuera un termostato que se ilumina para avisar de que algún desajuste se está produciendo en el sistema ecológico ${ }^{3}$. Es el papel del ritual como aviso que comunica eficazmente algún desequilibrio del sistema. Este importante papel, que además es de orientación, era ya señalado por R. H. Lowie en 1924 respecto a la religión, y desde el punto de vista ecológico, es decir considerado como un sistema, el primero en justificarlo es P. Collins (Collins, 1965), seguido por R. Rappaport (Rappaport, 1968) y A.Vayda (Vayda 1969). Antes que ellos Brooke Thomas hablaba ya de cómo las respuestas comportamentales iban dirigidas a producir variaciones en el entorno, estaban ordenadas jerárquicamente respecto al sistema ecológico y consistían en ser respuestas adaptativas de los organismos a las perturbaciones del entorno. Además tales respuestas pueden ser tanto individuales como sociales o intergrupales, porque son mecanismos sistémicos de regulación, concepto en el que después insistirá repetidamente Rappaport.

El papel de orientación señalado por P. Collins está representado por planteamientos distintos a lo largo del siglo pasado y, según mi criterio, completa la visión 
de la religión como un hecho social coercitivo, dependiente únicamente del concepto de norma social, típicamente durkheimiano. Desde mi punto de vista la orientación de las acciones replantea no sólo el objetivismo del autor, sino que pone el acento más bien en las acciones humanas y en su práctica, en el sentido de que es su orientación como direccionalidad y jerarquía del sistema ecológico la parte que se juzga hoy más importante a la hora de concederles valor y credibilidad, sobre todo si éstas son comportamientos colectivos como sucede en los rituales.

Tengo un aprecio especial por los rituales de nueva creación o las revitalizaciones, porque son los que pueden ejemplificar y también contradecir los planteamientos teóricos de mayor peso que se han hecho con respecto al tema. Intentemos aplicar, en este sentido, algunas de las observaciones realizadas sobre las acciones ciudadanas que tuvieron lugar en torno al 11-M de 2004, cuestionando si tales comportamientos fueron el comienzo de un ritual laico o ciudadano.

\section{ALGUNAS CUESTIONES TEÓRICAS Y DE DEFINICIÓN}

Sería difícil aplicar el modelo de análisis que los ecólogos humanos utilizan en sociedades "simples" donde es fácil comprobar y medir las variables medioambientales y las formas de producción y examinar la relación sistémica que tienen los comportamientos sociales y culturales en ella, donde se manifiesta el ritual como un importante mecanismo regulador. En las sociedades urbanas estas relaciones son enormemente complejas y las variables tecno-medioambientales aparecen cortocircuitadas y a su vez imbricadas en circuitos cada vez mayores en que se funden múltiples nichos ecológicos. Todo lo cual impide un seguimiento rápido de las transformaciones materiales, sin embargo el hecho de la aparición de este tipo de fenómenos de nuevos rituales hace pensar que realmente es un recurso de la humanidad, que aparece en momentos necesarios para la restauración del equilibrio. Veamos por ello la definición que Rappaport ofrece de lo que es un ritual en su última obra.

Cabe preguntarse si los acontecimientos del 11-M constituyen un ritual, o bien tan sólo un ceremonial. Para ello voy a repasar cada una de las características que atribuye a un ritual en la citada obra:

Observemos en un primer acceso algunos problemas que nos plantea el hecho de adjetivar ritual a las acciones que giran en torno a los sucesos del 11-M.

Cuando Rappaport en su último libro enumera las principales características de la forma ritual, afirma que el ritual es codificado por alguien diferente de sus participantes y en los casos en que no es así el autor afirma que los participantes renuncian a su autoría. Este sería el caso con el ritual creado en Atocha, basado en los sucesos del 11-M, cuyos participantes y codificadores fueron anónimos en tanto que creadores del mismo, aunque pudieran identificarse individual o colectivamente muchos de ellos. Lo principal desde esta óptica es que renuncian colectivamente a la autoría del ritual.

Atribuye además al ritual la formalidad como decoro, queriendo significar las actitudes de respeto que rodean todo ritual. En este sentido, era apreciable un recogimiento expresado por el silencio absoluto, las ofrendas llevadas, y las actitudes de respeto de quienes se acercaban, sobre todo, a la parte central de cara a la estación de cercanías, aunque tan sólo permanecieran allí unos breves minutos. 
Nos habla de inmutabilidad, más o menos, del ritual una vez creado. Y esta característica alude a la repetición que es propia de los comportamientos rituales, cuando ellos tienen lugar. En este sentido he podido observar algunas variaciones a lo largo de los meses siguientes al atentado, pero lo que considero más importante observar es cómo se repetían las visitas y ofrendas periódicamente, sobre todo los fines de semana y los días 11 de cada mes.

Asigna a un ritual la importancia que merece la propia ejecución ritual. Solo existe un ritual si hay ejecución ritual de unos órdenes litúrgicos (liturgia significa trabajo público según Jane Harrison (Harrison, 1913) ${ }^{4}$. Sin embargo este orden heterónomo que Rappaport exige como condición del ritual no se produce en la conmemoración del 11-M, puesto que nace espontáneamente de los ciudadanos y no es heterónoma, sino autónoma, como sucede siempre que aparece una creación e incluso una revitalización ritual. Respecto a esta característica el ejemplo que propongo de la creación del ritual sobre los sucesos de Atocha, se produciría sin duda un cuestionamiento respecto a si esos sucesos constituyen un ritual o tan sólo un ceremonial, problema que es debatido para otros casos por un buen número de antropólogos, que cubren la segunda parte del siglo pasado, como M.Wilson (Wilson, 1955), R. Firth (Firth 1976b), R. Rappaport (Rappaport, 1979), C. Bell (Bell, 1992), y R. Rappaport (Rappaport, 1999), etc.

Lo que creo que opinaría Rappaport, si se sometieran a examen las características declaradas por él, es que se trata de un ceremonial y no de un ritual. La razón fundamental consiste en que para este autor los rituales propiamente dichos son religiosos, aunque él alude a algunas excepciones. El modelo que emplea para los análisis y sus ejemplos preferidos son también religiosos. Sin embargo yo no opino de igual manera por variadas razones y desarrollaré esta argumentación en el mismo sentido más adelante.

M. Wilson decía que para establecer la diferencia entre ceremonial y ritual, se remitía a la prueba de que el ceremonial puede ser la reproducción de una formula escrita, mientras que el ritual no se deja someter a lo escrito porque no lo necesita, puesto que lo fundamental en él es su ejecución misma, cuya norma no siempre esta escrita. Argumentos en parecido sentido son aportados por Rappaport muchos años después.

Por último, se refiere el autor a otro tipo de formalidad que también es propia del ritual, sería una formalidad que se opone a la eficacia física o material inmediata, a la que también se refería E. Leach en el mismo sentido al hablar de los Kachin. Efectivamente el ritual creado en Atocha tampoco pretendía tener una eficacia material directa, sin embargo las acciones sociales siempre tienen repercusiones y las acciones rituales especialmente, en tanto que ejecutan muchas veces pacto social.

Pueden recordarse también algunas afirmaciones de V. Turner que aluden a los importantes efectos del ritual como integrador de las relaciones sociales aunque, como es sabido, ambos autores mantienen importantes diferencias teóricas.

Frente a las características que Rappaport atribuye a todo ritual, intento defender aquí que las manifestaciones sobre el 11-M constituyen un ritual incipiente, aunque no se acoplen del todo a algunos puntos de los que Rappaport propone.

Veamos algunos de los elementos que podrían constituir el disenso del autor:

En primer lugar, podemos comprobar que no posee comportamientos "estilizados", en el sentido de los comportamientos especiales que acompañan un itinerario en un ritual, por ejemplo religioso, aunque sí los hay repetitivos como en todo ritual. Creo que deben considerarse así los continuados ofrecimientos de: velas, mensajes y flores en un primer momento, o de mensajes, velas, peluches, flores, etc. en un segundo momento. 
En segundo término, es creado por los mismos que los ejecutan en los primeros momentos, aunque con la salvedad aducida más arriba, es decir, el hecho de que sus autores renuncian a su autoría. (Esta es una característica que en Rappaport no está desarrollada lo suficiente en su propio texto desde mi punto de vista $)^{5}$.

Además los rituales no se crean en muy pocas ocasiones, como el autor afirma refiriéndose a rituales religiosos, sino tantas cuantas es necesario, por ejemplo el ritual creado por los ciudadanos en torno al 11-M, y pueden verse también los ejemplos de las revitalizaciones durante la transición política y la consolidación democrática en España ${ }^{6}$.

Tampoco hay comportamientos canónicos previos, puesto que es la creación de un nuevo ritual perteneciente a los ciudadanos y son ellos quienes en un primer momento codifican el ritual como consideran mejor, porque no dependen de una autoridad exterior a ellos, sino los hechos son producto de un comportamiento voluntario y expresivo que es no sólo una crítica, sino una resistencia en la medida en que implica un comportamiento.

Se puede decir además que los rituales son en la actualidad igual de importantes si son laicos. Incluso sostengo frente a Rappaport, que es precisamente su condición de laicidad, como sustituta de los comportamientos religiosos la que fomenta su actual proliferación y plausibilidad por hacerse más necesarios como reguladores de los comportamientos frente a las fluctuaciones de los sistemas cada vez más frecuentes.

Señalar además que constituye un ritual del todo nuevo, nace de acciones individuales continuadas, aunque no simultáneas en el tiempo sino sucesivas, pero colectivas en ese sentido. Además se expresa mediante referentes a imaginarios colectivos (víctimas inocentes y fortuitas, representantes de cualquier urbano usuario de transportes públicos). Todo ello muestra el papel creativo de los nuevos comportamientos culturales, que lo acercan a algunas tesis de C. Castoríadis, cuando habla del imaginario radical (Nero, 2003).

Otra importante característica es el espacio como variable y el lugar utilizado para el ritual como indicador (algunos autores hablan de que el espacio es una de las principales coordenadas de todo ritual $)^{7}$. En este sentido la estación de Atocha, constituye un indicador al ser analizado y supone un cuestionamiento de lo religioso como algo vinculado a cualquier institución. Su laicidad se refleja en la voluntad de ritualizarlo preferentemente allí donde sucede y sus oficiantes principales eran los participantes mediante sus sucesivas ofrendas en condiciones de igualdad.

Por último, podría objetarse en contra de su consideración como ritual, el hecho de que las cantidades de energía que se pierden no son suficientes como para necesitar el sistema ecológico de un ritual como regulador, pero el duelo provocado por las pérdidas humanas tiene muchas características que comparte con los rituales.

Una prueba de esta tesis consiste en preguntarse ¿Cómo pudo mantenerse en condiciones tan precarias un ritual ciudadano y autónomo durante varios meses, sin aparente organización, ni mantenimiento, ni conservación, usando tan sólo los servicios de limpieza habituales y habiendo sucedido entre tanto un par de pequeños incendios, por la cantidad y densidad entre las velas y debido al plástico que las recubría? Supongo que la respuesta más adecuada parece ser, que se mantuvo a causa de la voluntad de todos los ciudadanos tanto visitantes como participantes en el incipiente ritual, hasta la fecha en que cambió su ubicación varios meses después. Considero esta característica muy importante ya que manifiesta con claridad una voluntad de permanencia, como sucede en cualquier ritual. 


\section{LOS ELEMENTOS MATERIALES}

Pasemos a continuación a examinar al menos algunos de sus elementos materiales indicativos más frecuentes que se repiten en la conmemoración de los sucesos de Atocha (y el resto de ubicaciones), como es la intención de este pequeño bosquejo, declarada más arriba.

Si se examinan de forma preferente los objetos materiales que han constituido este ritual, he podido comprobar que consistían en: velas, mensajes escritos en soportes libres sobre todo en papel, flores, pancartas, imágenes religiosas, peluches, caretas de escayola en igual número al de víctimas mortales, cruces, banderas, cuadros, esculturas y adornos creados artesanalmente para la ocasión, que suelen incluir dentro sus propios mensajes. También ropas especialmente significativas, que se llevaron puestas durante las tareas de ayuda a las víctimas y que estaban utilizadas de manera icónica. Por último un pilar que sostenía velas y caretas.

El orden expuesto respecto a los objetos materiales mencionados intenta reflejar su grado de representatividad por haber sido cuantificados los objetos en repetidas ocasiones, en las ofrendas dedicadas a las víctimas en la estación de Atocha ${ }^{8}$.

Muchos de estos objetos forman parte o representan elementos naturales especialmente: velas (asociadas usualmente a la energía, recurso de primer orden), o también las flores, cuya preferencia por ellas, algunos etólogos atribuyen a que suelen ser un primer indicador de alimento para humanos $\mathrm{y}$ animales, recordando algunos importantes aspectos del comportamiento animal.

Peluches ofrecidos por los niños de los colegios, y también por obsequios privados. Está ofrenda de peluches viene a coincidir con muchos de los mensajes expresos que aludían a las víctimas adjetivadas cariñosamente como babys e inocentes en un tono familiar.

Graffitis y trabajos artesanales, con frecuencia máscaras, maquetas o esculturas endurecidas con yeso, que en los casos más elaborados eran producto de colectivos diversos, o bien de compañeros de las víctimas, o de otros colectivos que se solidarizaban. Estos presentes solían incluir mensajes.

Otros de los índices estaban generalmente representados por prendas que representaron una gran ayuda durante las difíciles tareas del rescate de heridos y muertos: chalecos del SAMUR, camisetas, u otras prendas en recuerdo de la ocasión.

Respecto a los mensajes ofrecidos, el segundo elemento en orden de importancia, sus textos reflejaban contenidos de paz, de apoyo respecto a las víctimas, los familiares e incluso la ciudad de Madrid, que aparecía representada en ellos de manera metonímica, según suele ser una característica en los rituales ${ }^{9}$. El siguiente contenido estaba representado por los mensajes políticos, unos generales contra las guerras y otros, bastante numerosos en los primeros momentos, contra el partido en el gobierno en esos momentos.

Le seguían en importancia los mensajes religiosos, después preguntas incontestadas sobre las causas del atentado. También estaban representados algunos mensajes de venganza que proponían un comportamiento para con los culpables a manera de ley del Talión y aunque eran poco numerosos, lo cierto es que también estaban representados, probablemente producto de unos primeros momentos de intenso dolor y por ello poco reflexivos. Autores como Fassin, podrían interpretar estos comportamientos referidos exclusivamente a una respuesta puntual de condolencia y adaptación frente al sufrimiento humano desde una óptica de la Antropología del sufrimiento. 
En último lugar incluyo los mensajes en lenguas extranjeras, como pueda ser el árabe, el rumano o el japonés, que reseño en último lugar por ser menos numerosos y no estar traducidos algunos de ellos. Opino que es importante reseñar la característica de internacionalidad, que también juzgo propia de este tipo de fenómenos, puesto que sobre lo que se testimonia con los comportamientos es sobre valores universales como el derecho a la vida, a la paz, la libertad de expresión de la ciudadanía, etc.

Los comportamientos de los ciudadanos en torno a las actuaciones del duelo, constituyen por sí mismas otro de los indicadores más importantes. Entre ellas hay que señalar el profundo respeto demostrado con respecto al lugar de las ofrendas, ya que en la muestra que se recortó para la observación en un lugar central de la estación de Atocha, llegó a crearse una separación entre el lugar destinado a las ofrendas, que permanecía en silencio y separado claramente del resto de la estación. Quienes se acercaban a aportar su ofrenda, lo hacían en silencio y respetuosamente permanecían allí un corto tiempo, después se retiraban. Nadie se atrevió a mover estos objetos durante meses, ni ningún cartel ni mensaje adyacente, aunque no se compartieran los contenidos de sus mensajes.

\section{TRASLADAR EL RITUAL A LA RED INFORMÁTICA}

En repetidas ocasiones me acerqué a la estación de Atocha para examinar el resultado material de aquel incipiente ritual ciudadano, y cuando hacía aproximadamente algo más de un mes desde su inicio, pude comprobar que entre los objetos rituales y dentro del recinto que hacía de altar, separado por balizas, pero en un rincón sin valla que era muy accesible, alguien había depositado unas pequeñas tarjetas que llamaron mi atención. Se trataba nada menos que de la pretensión de trasladar el ritual a la red. En ellas aparecía una dirección electrónica con los datos pertinentes para quien quisiera conectarse a cualquier efecto en relación a la conmemoración de los sucesos del 11-M. ¿No fue esto un intento de trasladar un ritual con un gran número de características propias, a un tipo de actividad, la informática, percibida falsamente como completamente niveladora e igualitaria? Se ha producido también durante este tiempo un intento de vaciamiento del ritual, ¿se trataba de trasladar el ritual a la red informática como escenario alternativo?, ¿Quién o quienes se escondían tras la red?, ¿usuarios frente al público anónimo de los media, algún grupo organizado?...

Debo decir, muy claramente, que un ritual no es comparable a una red informática, aunque esta pueda tener algunos efectos igualitarios y actualice la comunicación entre usuarios de manera continuada, inmediata y rápida, cosa que de ningún modo estoy negando, pero sobre todo quiero señalar la principal característica que los diferencia. Consiste en que un ritual comunica para todos y casi siempre por medio de elementos materiales, tomados de la naturaleza, cuya transformación en símbolo depende del desarrollo del ritual mediante acciones, como comportamientos humanos significativos, es decir como acciones comunicativas a muchos niveles y de muchos tipos, que algunos antropólogos han llamado acción simbólica (puede verse al respecto G. Bateson, 1972 y C. Geertz, 1973), a pesar de que estos autores, sobre todo Geertz no tiene un planteamiento material del ritual, sino interpretativista.

El ritual es un comunicador muy completo para la sociedad, aunque también para los animales. Con completo quiero decir que comunica cosas importantes para todos, a veces cosas que tienen que ver con la continuidad y supervivencia de la especie. Y cuando 
digo para todos, quiero decir que también están incluidos los que no tienen acceso a la red, que son en estos momentos todavía más que los que la tienen en este país y no digamos en el mundo. Mi insistencia en esto se opone a las visiones algo futuristas que consideran que hoy todos vivimos en un mundo actualizado por la red en tiempo presente.

Unos meses después del atentado, el 9 de junio de 2004 se consiguió el intento. Se sustituyen los objetos ofrecidos y se pone en funcionamiento en Atocha una especie de panteón virtual del 11-M con una especie de video-world, donde aparecía un lugar para un: Espacio de Palabras, que se ofrecía en dos grandes pantallas fijas al suelo, junto a unas columnas simuladas, que aún durante bastante tiempo recogieron los mensajes manuscritos que continuaban ofreciendo voluntariamente los ciudadanos. El espacio de palabras no sólo recogía textos, sino también imágenes y dibujos de los que se hacía un uso emblemático y simbólico, creando una especie de comunidad virtual, donde aparecía un espacio de imágenes que incluía - además de los mensajes - poder dejar una impresión de la huella de la mano de quienes quisieran adscribirse a la red como usuarios. También se hacía repetida propaganda icónica de RENFE, uno de los patrocinadores del proyecto. En el proceso de traslado a realidad virtual aparecían símbolos que habían sido muy politizados y manipulados durante los últimos años, como eran la forma de los lazos negros o las manos blancas, utilizados por el PP contra los atentados etarras, pero tales símbolos en el nuevo contexto de crecimiento de un ritual demasiado espontáneo, cobraban una amplitud que excedía la representación e intencionalidad de los partidos políticos que los pusieron en marcha, intentado significar, en mi opinión, tan sólo una adhesión individual a la paz.

A pesar del rechazo inicial que provocó la sustitución del voluntario duelo en la estación de Atocha, por el gigantesco panteón conmemorativo que incluía una lápida por los ausentes y comunicación mediática virtual a la que nos referimos que ocupaba el lugar de las ofrendas, en un par de años se llegó a disponer de poco menos de 60.000 mensajes electrónicos aproximadamente. Probablemente lo que desmotivó la participación ciudadana en un primer momento fue, sobre todo, las decisiones de los poderes públicos por los cambios continuados de ubicación, ya que se llevó primero a la fuente de Atocha (un monumento improvisado compuesto por árboles y llamado "Bosque de los ausentes") y después al Retiro (que fue llamado "Bosque del recuerdo"), además del directivismo a que estuvo sometido el proceso de la conmemoración. Sumándose a ello la conversión del ritual en algo virtual, que al pasarlo a un programa informático lo sitúa en otro plano temporal distinto al que establece de modo propio cualquier ritual.

Con el cambió de ubicación a la fuente de Atocha se había violado una de las coordenadas propias de cualquier ritual: el espacio. Con su transformación en un programa informático se había violado la otra: el tiempo, convirtiéndolo no en un tiempo durativo, sino en la trampa de un tiempo puntual y en cuanto tal irreal. Todo ello parece expresar la continua pugna que se establece con frecuencia entre las creaciones culturales de nueva aparición, que suelen implicar decisiones políticas individuales y colectivas, cuyo reflejo pueden ser estos comportamientos públicos por un lado, y por otro los poderes fácticos, pero existía una voluntad de continuidad y permanencia por parte de los ciudadanos, que fueron ajenos a estos continuos cambios. 


\section{EL CONTEXTO POLÍTICO INMEDIATO}

Como es bien conocido los sucesos del 11-M, se enmarcaron en el contexto en el que España interviene en la guerra contra Irak como aliada política de Estados Unidos, junto con otros países. El Reino Unido se muestra también como uno de los más beligerantes, para una guerra que en España no había sido consultada ni al parlamento ni a los ciudadanos y que desencadenó en muchas ciudades europeas las manifestaciones más multitudinarias de su historia. En España estas manifestaciones se repitieron en forma de marchas en las principales ciudades y fueron además acompañadas de concentraciones en los municipios, para ellas había un respaldo del $91 \%$ de la población según la información de la prensa más vendida en esos momentos (El País y El Mundo). Participaba además nuestro país en el intento de desmantelamiento de Al Qaeda.

El atentado se instala dentro de un ambiente tenso, cuya primera muestra tiene lugar casi diez meses antes en la Casa de España en Casablanca el 16 de Mayo de 2003, con cinco explosiones que produjeron cuarenta y tantos muertos además de cien heridos y donde mueren también algunos españoles. Detrás del atentado estaba Al Qaeda, que ya penalizaba con ello a España por primera vez por su participación en la guerra contra Irak. El incidente, que fue también muy sangriento, no fue visto como un aviso en aquel momento.

Los sucesos de Atocha se enmarcan en pleno periodo electoral, cuando faltaban tres días para las elecciones generales. El grupo terrorista atacó las estaciones de Atocha con varias bombas ${ }^{10}$, en Atocha, otra en la calle Téllez, otra en El Pozo y otra en Santa Eugenia en la línea ferroviaria que va de Alcalá de Henares a Madrid. Los resultados del atentado fueron especialmente cruentos y hubieran podido serlo más si hubieran explotado otras varias bombas, cuyas explosiones se preveían simultáneas en el AVE y que no llegaron a tener lugar. Se produjeron a las 7:37 de la mañana en un punto central de comunicación de trenes: (Ave, Talgo, cercanías, etc.), metro, estación de autobuses, amplia parada de taxis, donde por la hora y el lugar, se concentraban un gran número de personas. Debido a lo desastroso de la masacre, los medios informativos unos minutos después se trasladan para informar sobre el acontecimiento, que permanece en primera línea de la noticia y en todos los canales de televisión con un bombardeo informativo acompañado de una alta audiencia, que dura aproximadamente algo más de una semana. Lo repelente del destrozo humano que se transmite por las imágenes televisivas afectan profundamente a la población, que manifiesta su solidaridad de manera voluntaria y libre, concentrando dentro y alrededor de toda la estación de Atocha, en un primer momento, un gran número de velas, mensajes de paz, condolencia y apoyo a las víctimas. Todas estas condiciones nos ponen en contacto con una antropología del sufrimiento señalando teorías como las de J. Davis, Kleinman y Kleinman y D. Fassin en relación con la adaptación.

Por otra parte varios autores han señalado la importancia que se concede en la actualidad a la vida humana, que ha quedado plasmada en la legalidad actual como un derecho humano fundamental. Ya Bryan Turner, aducía en este sentido, que si hay pocos valores que permanecen en la sociedad laica, el que se mantiene de forma bien patente es el del valor de la vida ${ }^{11}$. Todo ello refleja una alta conciencia y madurez de los valores morales, que reivindican el derecho a la vida como algo fundamental.

El análisis de los comportamientos ciudadanos y el de los elementos materiales en estos fenómenos en torno al duelo, se revela como una sintaxis específica que compone el 
nacimiento de este ritual, en que sus elementos son capaces de comunicar de una forma altamente eficaz para todos, mostrando los parámetros del aquí y ahora.

\section{EL LUGAR DEL RITUAL COMO INDICADOR: EN EL CENTRO DEL CENTRO DE LA CAPITAL DEL PAÍS}

Si se consideran estas acciones como un ritual que empezaba a producirse, es de capital importancia examinar el espacio y también el lugar donde se produce, por constituir este un indicador central de comunicación. En este caso la propia estación de Atocha que es un centro material de comunicaciones que enlaza al menos cuatro formas de transporte: trenes, metro, autobuses y taxis, se convierte de forma rápida en el indicador material principal, que comunica eficazmente el dolor por las pérdidas de las 192 vidas humanas, representadas en este incipiente ritual, que se convirtió de la noche a la mañana en un improvisado lugar de testimonio y conmemoración a las víctimas. En un sitio significativo de la ciudad, cuyos participantes son los ciudadanos que libre y voluntariamente quieren honrar su memoria, representando con sus comportamientos la indefensión del urbano de a pie en una sociedad de masas, mediante su identificación repetida con las víctimas a través de los mensajes. Uno de los más claros y repetidos, que refrendan esta afirmación, era el de "todos íbamos en ese tren", cuyo texto aparecía reflejado como titular en varios diarios la mañana siguiente.

El buscar los responsables políticos del brutal atentado era otro de los textos que más se repetían en los mensajes escritos en un primer momento, inmediatamente después del atentado. En aquellos momentos era una queja muy politizada, la que ocupaba la mayor parte de los mensajes escritos, depositados en el lugar central que ocupó el sitio preferente de las ofrendas a las víctimas y que tomé como muestra para el trabajo de observación del fenómeno. Todo ello culminó en la multitudinaria manifestación del 13 de Marzo en apoyo a las víctimas de amplio debate político.

El comportamiento ciudadano fue en todo momento un ejemplo de desarrollo humano respecto a solidaridad, respeto a la opinión de los otros y a educación cívica. Estaba representado por la pluralidad y diversidad de pancartas y mensajes en los lugares de conmemoración, que todos respetaban. El atentado fue tan impactante, que se convirtió de algún modo en una aguda crítica al gobierno saliente desde aquellos momentos por su participación en la guerra contra Irak, a los ojos de los inmediatos votantes de las elecciones generales que tuvieron lugar tres días después y que hicieron cambiar de gobierno y partido político a la nación.

Por otra parte fueron las decisiones del gobierno, los poderes públicos y las empresas durante el verano de 2004, los que decidieron canalizar el incipiente ritual de otra forma (introducción de los mensajes y los contactos por internet en la estación de Atocha y la plantación de un árbol por víctima en el Retiro) eliminándolo como tal al cambiar su emplazamiento y disociar sus funciones ${ }^{12}$.

\section{EL PAPEL DE LA CULTURA Y SU SENTIDO EN LA SOCIEDAD ACTUAL}

Mi intención respecto a este tema consiste en plantear la cultura como creación dentro de su contexto histórico concreto, por ello prefiero una selección de elementos de la 
cultura viva actual, como es el caso que se analiza aquí y es preciso decir unas palabras que permitan situar los fenómenos analizados, para ver si ellos son una respuesta de comportamientos mediante acciones colectivas, como una forma adaptativa más o menos puntual frente al desastre de Atocha, como podría seguirse de un planteamiento de la antropología del sufrimiento, donde tendría su lugar el nacimiento de un nuevo ritual ciudadano. El hecho es que desde la década de los setenta y con mayor claridad desde los ochenta, asistimos a una proliferación de movimientos ciudadanos que culminan muchas veces en comportamientos testimoniales y simbólicos, donde uno de los elementos más repetidos es el que conlleva mensajes pacifistas. En ellos con frecuencia se revelan y patentizan, mediante una lectura material de sus elementos, los parámetros tecnoecológicos y tecnoeconómicos de las nuevas situaciones, como algo propio de las alternativas de la cultura, de forma similar a como sucede en cualquier ritual. La lectura de los elementos materiales como indicadores y de la utilización del espacio dentro del marco social también puede aportar importantes datos revelándose muy importantes, pero sólo si se consolidan estos acontecimientos como un ritual, propondría la necesidad del análisis del tiempo.

Puede ser también objeto de reflexión observar que los rituales colectivos que se continúan desde el comienzo de la humanidad hasta la forma de sociedad llamada 'industrial', se han mantenido durante muchos siglos, afectando a las sociedades históricas. Durante varios siglos en la sociedad europea ha ido produciéndose un cierto desplazamiento, en que vemos como estos comportamientos se sustituyen por formas de conciencia individual coincidentes con la emancipación de pensamiento representada por primera vez en Europa por la reforma protestante y el desarrollo de la burguesía comercial principalmente, que posibilitan el desarrollo de la filosofía como un pensamiento autónomo, donde podríamos decir que la modernidad hace inclinar la balanza de las manifestaciones religiosas del lado de la preferencia por planteamientos individuales de la religión. Sin embargo fenómenos de índole político: cambios de regímenes políticos, nuevas configuraciones de naciones, regiones, comunidades, localidades, etc., hacen despertar fenómenos de identidad que van de la mano de intereses diversos. Por todo ello al menos, asistimos en la actualidad a unos momentos en que hacen su aparición nacionalismos y regionalismos en épocas ya recientes. Si a ello unimos el proceso creciente de globalización, referida por todos en la ciencia social últimamente, unido a los continuos procesos de migraciones transnacionales, observamos que tal globalización es inseparable de nuevos fenómenos que desarrollan movimientos locales. Ello implicará fenómenos de identidad, reivindicadores de políticas más adecuadas a las necesidades de los momentos presentes. La proliferación de fenómenos sociales que se sitúan entre lo global y lo local, agudizan el sentido político y ciudadano de los movimientos sociales, que van cobrando una conciencia cada vez más desarrollada de los valores humanos.

Este panorama vuelve a inclinar la balanza del lado de los colectivos, que no sólo funcionan de este modo, sino que se piensan como tales ${ }^{13}$. Una de las manifestaciones frecuentes de estas nuevas formas sociales suelen ser movimientos que unas veces son rituales, otras ceremoniales y algunas otras formas intermedias ${ }^{14}$.

Una visión generalizada de estos problemas es la recogida por C. Taylor (Taylor, 1993 ) en su bien conocido artículo "Multiculturalismo y la política del reconocimiento" cuando nos habla del giro subjetivo característico de la cultura moderna, aunque está orientada al debate sobre el liberalismo y al problema del reconocimiento de la identidad, donde las oscilaciones entre lo subjetivo o individual como diferencia, y lo colectivo 
referido en las contradicciones normativas de la política liberal, son también deudoras no sólo del debate, sino de los fenómenos políticos que las provocan.

Volviendo a nuestro tema, creo interesante cuestionarse sobre estos nuevos fenómenos colectivos, todos ellos civiles o laicos en su origen, que constituyen importantes respuestas de índole comunicativa en la medida en que se ritualizan total o parcialmente. Según mi experiencia en el análisis de estos fenómenos todos ellos son una protesta ritualizada frente a diversos elementos que crean estrés medioambiental, pueden ser de condolencia frente a muertes masivas debidas a fenómenos políticos, o a causas naturales. También pueden ser respuestas frente a políticas que producen paro, pobreza y desaparición de formas de producción históricas que suelen mantener a los más pobres, como sucede con relativa frecuencia al implementarse nuevas formas de producción y mantenimiento del ganado. Esto es señalado también por Kottak, (K. Kottak, 2000) de una forma algo más amplia, no sólo refiriéndose a rituales, sino a fenómenos de tipo cultural en general $^{15}$. Aparecen con frecuencia también como respuestas pacifistas masivas frente a políticas de agresión no deseadas por los ciudadanos. Actualmente comienzan asimismo a configurarse en un sentido cultural como participaciones ciudadanas a veces asociadas a fiestas. Opino que constituyen también respuestas de resistencia por la inermidad ciudadana frente a las políticas, creando formas culturales de las que se sienten protagonistas como compensación.

Todo ello puede hacer pensar que se ha producido en las últimas décadas, y sobre todo en los últimos años, un desplazamiento del protagonismo de la conciencia individual como credo o ética, a estas formas patentes de movimientos sociales como nuevas creaciones, que manifiestan varias cosas a la vez a través de sus mensajes. Ciñendo el análisis a los sucesos de Atocha, expresan unión y condolencia por los fallecidos, acusaciones a los considerados culpables y testimonio ciudadano de protesta contra las malas políticas que secundan agresiones imperialistas, reclamando la paz en su lugar. Todo ello se realiza de forma pacífica, testimonial y solidaria, pero erigiéndose como testigo continuamente vivo que comunica, además de la condolencia, la insatisfacción, la resistencia y el recuerdo para con las víctimas, todo de una vez. Otra característica de los rituales es que nunca se producen aislados, sino en grupos. Esta fue la exacta situación de los sucesos del 11-M, que se vincularon a un gran grupo de manifestaciones por la paz y contra la guerra de Irak en las principales ciudades europeas durante los días inmediatos.

Estos movimientos son muchas veces culturales o testimoniales en el sentido de algo más amplio que el político en su origen, pero no en sus resultados que pudieron verse políticos con resultados inmediatos. El hecho de nuevos y frecuentes fenómenos de creación cultural se produce además como algo propio de las democracias organizativas, donde tiene lugar un alejamiento cada vez mayor de la gestión política de los ciudadanos, que les hace sentir cada vez más lejos de la participación en ella, percibiéndose incapaces de tomar ninguna decisión respecto a los asuntos públicos, sobre todo en sistemas políticos en los que hay una fuerte especialización política y burocrática centralizada.

También puede interpretarse este ritual de reciente creación, como una orientación de acciones incapaces de ser canalizadas por completo de otra forma en aquellos momentos por lo traumático de la situación, como una respuesta al desastre en su sentido ecológico. Donde el papel de la información constituida por el ritual se integra mediante los parámetros tecno-medioambientales, potenciando su eficacia. De este modo las acciones rituales vuelven a cobrar actualidad como un comportamiento recurrente en la historia de la humanidad que es capaz de comunicar para todos, y sobre todo, en los 
tiempos actuales para los más humildes. Comunicando de forma más universal que otros medios, asumiendo la cultura en la actualidad, cada vez con mayor frecuencia, el antiguo papel reservado a la religión un tiempo atrás.

\section{NOTAS}

${ }^{1}$ B. Anderson, 1986.

${ }^{2}$ El caso de M. Weber, señalando la importancia de las acciones humanas es alguien de quien somos deudores teóricos, pero que no trato a este respeto por no considerar él las acciones colectivas, ni su inclusión en el sistema ecológico humano, condición imprescindible en el ritual.

${ }^{3}$ R. Rappaport, 1968.

${ }^{4}$ Citada por R. Rappaport, 1999.

${ }_{6}^{5}$ Puede verse al respecto R. Rappaport, 2001, p. 67.

${ }^{6}$ Jimeno Salvatierra, 2004.

${ }^{7}$ D. Sperber, en M. Izar y P. Smith, 1989.

${ }^{8}$ Para construir este listado he seleccionado tan solo una muestra constituida por lo que podría llamarse el lugar central dedicado a las víctimas, donde en la actualidad se ha construido un gran mural oficial que contiene los nombres de muertos y heridos. Para construir este listado he seleccionado tan solo una muestra, obtenida mediante un prolongado seguimiento de trabajo sobre el terreno. Estaba constituida por lo que podría llamarse el 'lugar central del duelo dedicado a las víctimas', enclavado en la propia estación de Atocha, en el primer piso, muy cerca de donde sucedió la catástrofe.

${ }^{9}$ Para aplicaciones de la metonimia a cuestiones antropológicas ver E. Leach, 1973.

${ }^{10}$ Para una descripción exhaustiva sobre el atentado ver: M. Marlasca y L. Rendueles, 2007

${ }^{11}$ B. S. Turner, $1984 / 89$.

${ }^{12}$ Posteriormente (2007) se ha construido un monumento en recuerdo a las víctimas del 11-M frente a la propia Estación de Atocha, frecuentado por las autoridades y el público en el aniversario de los sucesos.

${ }^{13}$ B. Anderson, 1986. Ver también A. Giddens.

${ }^{14}$ Rappaport reconoce en su última obra la existencia de formas intermedias entre ritual y ceremonial.

${ }^{15}$ C. Kottak, 2000. Puede verse esta tesis ampliamente aplicada a la cultura en Jimeno Salvatierra, 2004 y 2006.

\section{BIBLIOGRAFÍA}

ANDERSON, B. (1986): Comunidades imaginadas, México, Fondo de Cultura Económica.

BATESON, G. (1972): Steps to an Ecology of Mind, New York, Ballantine

BELL, C. (1992): Ritual Theory, Ritual Practice, Oxford, Oxford Univ. Press.

CASTORÍADIS, C. (1975/89): La institución imaginaria de la sociedad, Barcelona, Tusquets.

- (1982/98): "La institución de la sociedad y de la religión" en Los dominios del hombre. Las encrucijadas del laberinto, Barcelona, Gedisa.

COLLINS, P. W. (1965): "Functional Analysis", en Man, Culture and Animals, Leeds, A. y Vayda, A.P. (eds.), Washington, America Association for the Advancement of Science.

DAVIS, J. (1992): “Antropología del sufrimiento", Rev. De Occidente, n 137, Madrid.

DURKHEIM, E. (1988): Las reglas del método sociológico, Madrid, Alianza.

- (1912/1993): Las formas elementales de la vida religiosa, Madrid, Alianza.

FIRTH, R. (1976b): Tikopía. Ritual and Belief, Boston, Beacon Press.

FRASER, N. (2003): "Social Justice in the Age of Identity Politics: Redistribution, Recognition and Participation", en N. FRASER, y A. HONNETH, Redistribution or recognition? A Political Philosophical exchange, London-New York, Verso.

GIDDENS, A. (1990): La teoría social hoy, Madrid, Alianza. 
- (2001): “Teorías para una nueva sociedad”, Madrid, Junio, Conferencias de la Residencia de Estudiantes (Castells, Giddens, Touraine).

GEERTZ, C. (1973/2000): La interpretación de las culturas, Barcelona, Gedisa.

HARRISON, J. (1913): Citada por R. Rappaport, 1999.

JIMENO SALVATIERRA, P. (2002/2004): Rituales de identidad revitalizados, Madrid, UAM, Colección de Estudios. Segunda edición ampliada, 2004.

- (2006): La creación de cultura. Signos, símbolos, antropología y antropólogos, Madrid, UAM ediciones.

KANT, I. 1963): Crítica de la Razón Práctica, Madrid, Victoriano Suárez.

KOTTAK, C. (2000): "La cultura y el desarrollo económico", en VIOLA, Antropología del desarrollo, teorías y estudios etnográficos en América latina, Barcelona, Paidós.

LEACH, E. (1976): Cultura y Comunicación, Madrid, Siglo XXI.

LOWIE R. H. (1924/76): Religiones primitivas, Madrid, Alianza.

MARLASCA, M. y RENDUELLES, L. (2007): Una historia del 11-M, Madrid, Temas de hoy.

MILTON, K. (1997): "Ecologías: antropología, cultura y entorno", Rev. Internacional de Ciencias Sociales, $\mathrm{n}^{\circ} 154$.

RAPPAPORT, R. (1975): "Naturaleza, cultura y antropología ecológica", en SHAPIRO, H. (ed.) Hombre, cultura y sociedad, México, FCE.

- (1999): Ritual and Religion in the Making of Humanity, London, Cambridge.

SPERBER, D. (1989): La función simbólica, en IZAR, M. y SMITH, P., Madrid, Júcar.

TAYLOR, C. (1993): Multiculturalismo y la "política del reconocimiento", Madrid, FCE.

THOMAS, R. B. (1973): "Human adaptation to a High Andean Energy Flow System", Pennsylvania State University, Occasional papers in Anthropology, $\mathrm{n}^{\circ} 7$.

TURNER, B. S. (1984/89): El cuerpo y la sociedad, México, FCE.

TURNER, V. (1967/1980): La selva de los símbolos, Madrid, Siglo XXI.

- (1969): The Ritual Process, Chicago, Aldine.

VAYDA A. P.; LEEDS A. y SMITH, D. (1961): "The place of pigs in Melanesian subsistence", en GARFIELD V, (ed), Proceedings of the American Ethimological Society, Seattle, Univ. of Washington Press.

\section{Breve currículo:}

\section{Pilar Jimeno Salvatierra}

Doctora por la UAM (1981), Actualmente Profesora Titular de Antropología social en la Universidad Autónoma de Madrid. Imparte los cursos: Símbolos y estructura social, Cultura y comunicación, y el Curso de Doctorado: Etnografía y Teoría en ciencias sociales. Ha sido Research Associate en la Universidad de Berkeley, California. Sus líneas de investigación: Análisis de fenómenos de identidad, Formas de articulación entre estructura social y cultura o ideología, Cultura y religión: ideología, política, comunicación. Problemas teóricos en antropología, Desarrollo, Análisis de fenómenos culturales en relación con políticas. Análisis de procesos turísticos e implantación de los mismos. Entre sus últimas publicaciones: Rituales de identidad revitalizados, UAM, ediciones, 2002. Reeditado en 2004 y La creación de cultura. Signos, símbolos, antropología y antropólogos, UAM, 2006. 